\title{
Do Manutata ao Uakíry: história indígena em um relato de viagem na Amazônia Ocidental (1887)
}

\author{
From "Manutata" to "Uakíry": indigenous history in a \\ travel report in the Western Amazon (1887)
}

Cliverson Pessoa ${ }^{1}$

DOI: http://dx.doi.org/10.20435/tellus.v17i34.457

Resumo: O coronel Labre atravessou do Rio Madre de Dios (Manutata) ao Rio Acre (Uakíry) em 1887. As descrições feitas pelo viajante informam sobre a situação de diversos grupos indígenas, seus caminhos, malocas/tabas e templos sagrados, registrados na língua dos próprios povos que habitavam a região. Este artigo propõe uma leitura desses dados históricos com enfoque na localização dos etnônimos e topônimos. O objetivo é reunir as informações históricas e etnográficas dos grupos indígenas que podem ser avaliadas à luz da antropologia, linguística e arqueologia.

Palavras-chave: história indígena; etnônimos; topônimos; coronel Labre.

Abstract: Colonel Labre crossed the Madre de Dios River (Manutata) to the Acre River (Uakíry) in 1887. The traveler's descriptions inform about the situation of various indigenous groups, their paths, "malocas"/"tabas" and sacred temples, recorded in the own language of the people who lived in the area. This article proposes a reading of historical data with focus on the location of ethnonyms and toponyms. The objective is to gather the historical and ethnographic information of indigenous groups that can be evaluated in the light of anthropology, linguistics and archeology.

Key words: indigenous history; ethnonyms; toponyms; colonel Labre.

${ }^{1}$ Universidade Federal de Rondônia, Porto Velho, Rondônia, Brasil. 


\section{INTRODUÇÃO}

O presente artigo analisa os escritos do coronel Antonio Rodrigues Pereira Labre em uma perspectiva interdisciplinar com enfoque nos etnônimos e topônimos, com a finalidade de gerar uma contribuição à história indígena amazônica. Labre atravessou do rio Madre de Dios (Manutata) ao rio Acre (Uakíry), cujo relato foi publicado em 1888 na Revista da Sociedade de Geografia do Rio de Janeiro sob o título Viagem Exploradora do rio Madre de Dios ao Acre. Um ano antes, Labre já havia publicado o Itinerário de exploração do Amazonas à Bolívia, que trata da mesma viagem, que começa no rio Purus, passa pelos rios Amazonas, Madeira, Beni, Madre deDios, Orton e finaliza no rio Acre. As descrições feitas pelo viajante, embora objetivasse mostrar vias de comunicações alternativas entre o Brasil e a Bolívia, acabaram por informar sobre a situação de diversos grupos indígenas, seus caminhos, malocas/tabas e templos sagrados, sendo esses registrados na língua dos próprios povos que habitavam a região.

Um complexo mapa sobre sua expedição foi publicado pela Royal Geographical Society de Londres (LABRE, 1889), no qual constam diversos etnônimos e topônimos indígenas que Labre enumerou entre os rios Madre de Dios e Acre. Logo, esta narrativa de viagem contém um dos mais expressivos relatos sobre os povos que ocupavam esses rios no século XIX. Métraux (1942, p. 1-4) arrola a mesma descrição junto a outros relatos e estudos antropológicos para esboçar a conjuntura etnográfica na fronteira Brasil-Bolívia, cujas informações apontam para um expressivo número de línguas indígenas, porém com poucos elementos materiais, especificamente arqueológicos, que pudessem explicar a trajetória dessa "multiplicidade de tribos". Nesse quadro, por exemplo, as bordas do sudoeste da Amazônia apresentam informações históricas e etnográficas de povos com afinidades mitológicas com os Incas, templos sagrados e artefatos "sofisticados". Foi conveniente para a etnologia americanista atribuir um centro difusionista no altiplano andino, que se disseminou pelas bordas das terras baixas amazônicas; outras características de povos da Bolívia oriental teriam sido disseminadas e compartilhadas pelos povos falantes da família linguística Arawak.

O mapa de Labre (1888) oferece a possibilidade de sobrepô-lo ao atual registro arqueológico da região, a saber, os geoglifos do Acre e as zanjas da Bolívia. O ponto central deste artigo é utilizar a narrativa de Labre para apontar um 
quadro representativo da ocupação indígena na região dos rios Madre de Dios e Acre. Dessa forma, é necessário expor e discutir essas informações históricas e etnográficas documentadas nos relatos oitocentistas.

A maior parte dessas informações foram reunidas no Handbook of South American Indians, manual que combina informações etnográficas, linguísticas, ecológicas e por vezes arqueológicas, dentro da etnologia americanista que propunha áreas culturais (STEWARD, 1963). Essa concepção foi fortemente criticada pela antropologia brasileira, que passou a priorizar a abordagem sobre a situação colonial, territorialização, parentesco, organização social, sistemas de classificação e cosmologias ameríndias (PACHECO DE OLIVEIRA, 1998; VIVEIROS DE CASTRO, 1996). Por outro lado, nos últimos anos, antropólogos, arqueólogos e linguistas têm utilizado a etnologia, etno-história, arqueologia, ecologia e linguística para entender a construção de identidades persistentes, apontar a formação de contextos etnogênicos, assinalar sistemas regionais, possibilitar a composição de histórias alternativas e iluminar a diversidade etnolinguística nas antigas terras baixas sul-americanas (AIKHENVALD, 2002; ERIKSEN, 2011; HECKENBERGER, 2005; HILL, 2013; HORNBORG; HILL, 2011; HILL; SANTOS-GRANERO, 2002; NEVES, 2011; NOELLI, 1998).

A leitura dos dados fornecidos pelo coronel Labre, com enfoque nos etnônimos e topônimos podem indicar importantes elementos de uma história indígena que pode ter se iniciado ainda no período pré-colonial. Não se trata de explicar as definições dos nomes, mas as implicações que esses possuem para assinalar as interações entre diferentes coletivos. Segundo Calavia Sáez (2013, p. 9), “os etnónimos não nos servem para ordenar a descrição, mas fornecem muitas pistas sobre o modo em que os nativos praticam a sua socialidade". Portanto o relato de Labre pode ser utilizado como um "códice" que conduz a historicidades mais profundas para além do que é visto entre os rios Madre de Dios e Acre em 1887. Logo, história indígena é entendida aqui como um procedimento interdisciplinar que interroga a documentação escrita (CAVALCANTE, 2011; FREITAS, 2004), e está inteiramente ligada à arqueologia e à linguística, seja para buscar na profunda história pré-colonial correspondências nas materialidades, seja para entender os etnônimos no contexto social.

A história indígena assume uma incessante busca pela continuidade e mudança entre o registro arqueológico e os povos indígenas, nas pistas das 
classificações etnolinguísticas, na análise histórica dos documentos produzidos por viajantes, mas sem perder de vista os processos coloniais em que os povos indígenas foram envolvidos. Em outras palavras, "fazer história indígena de longa duração envolve coligir resultados de um grande número de disciplinas, visto que cada especialidade contribui com elementos fundamentais para um entendimento menos essencialista e mais relacional/dialético de nosso objeto" (CORRÊA, 2013, p. 28).

\section{DO MANUTATA AO UAKÍRY}

Quando o coronel Labre atravessou do rio Madre de Dios ao rio Acre, sem seguir o curso de um rio, embora encontrasse muitos arroios, regatos ou várzeas cobertas, grande parte do território que enfrentou era de terra firme, onde ele mencionou taperas, tabas, malocas e povoados com topônimos identificados na língua dos povos locais (Figura 1). Em 1 de agosto de 1887, Labre saiu de Ribeira Alta (Ribeiralta) na Bolívia, em direção ao Porto de Maravilha, rio Madre de Dios acima. Acompanhado de 18 homens não índios e 15 índios Araúna, partiu do Porto de Maravilha em direção ao rio Acre buscando um caminho alternativo que ligasse a Bolívia ao Brasil. 


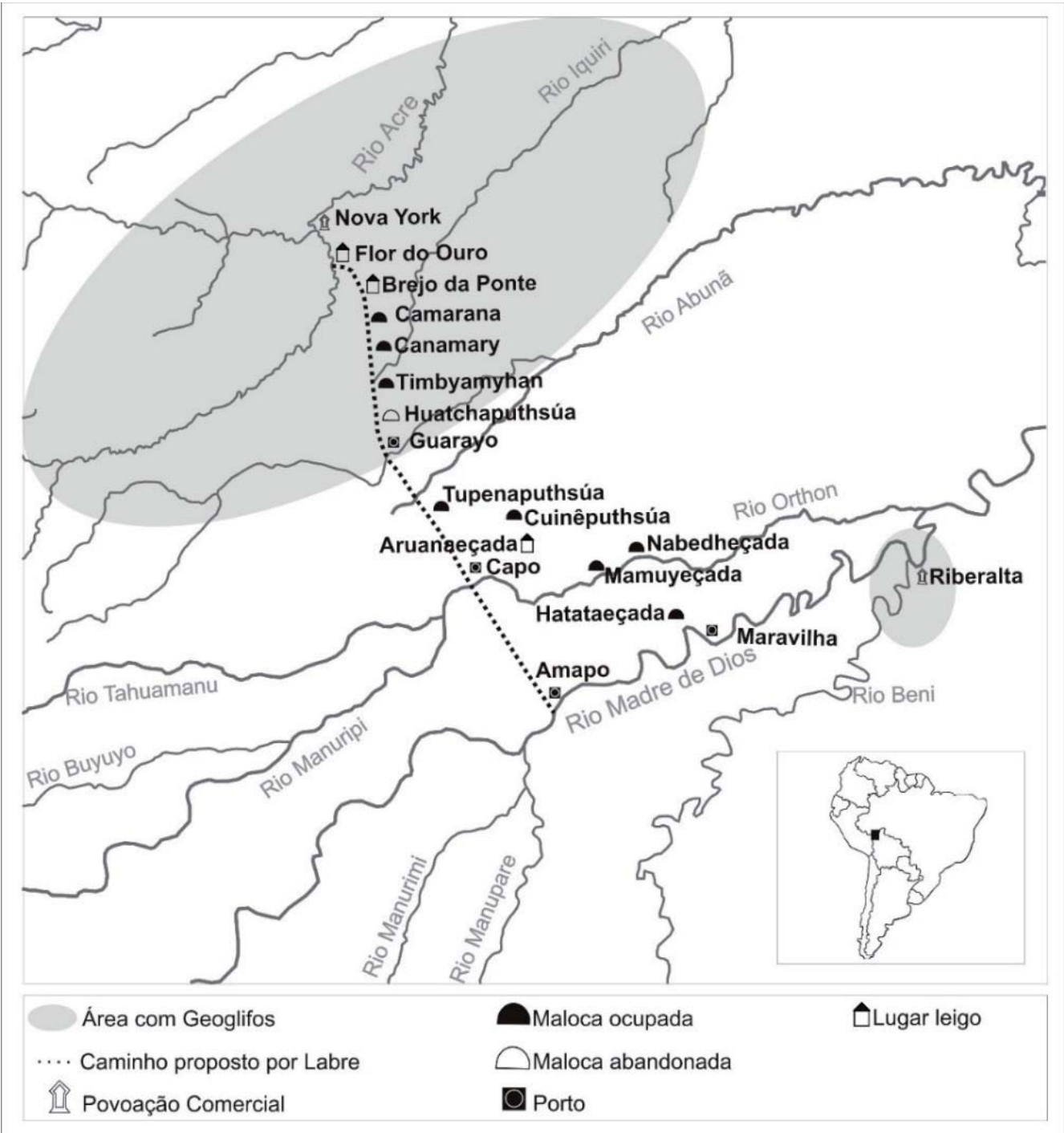

Figura 1 - Topônimos fornecidos por Labre entre os rios Madre de Dios (Manutata) e Acre (Uakíry).

Fonte: Antonio Labre, 1889.

Os primeiros Araúna que sua expedição encontrou na tapera Hatataeçada, cujo chefe era Equári, estavam "pacificados" e em contato com os seringueiros (LABRE, 1888). A partir do rio Orthon (Thanámanu), os expedicionários chegaram ao porto Budha. Após atravessar o rio Orthon, Labre encontrou uma taba 
abandonada de nome Baiheçada que possuía uma pequena cabana para guardar ídolos (LABRE, 2016, p. 189), e horas depois chegaram à maloca de nome Nabedheçada dos índios Araúna: "tem idolos e templos; estão installados de pouco tempo; usam tangas e camisolas; os homens usam os cabellos compridos e trançados em fórma de chicote, á chineza; vi uma mulher semi-branca tendo fórmas bellas" (LABRE, 1888, p. 108-9). Nabedheçada tinha como chefe Tata-Chumo² que passou a integrar a expedição junto com sua mulher e mais quatro índios.

No dia seguinte, a expedição do coronel esteve em outra povoação de nome Mamuyeçada dos Araúna:

Mamuyeçada é uma maloca de 100 e tantos a 200 habitantes; tem fórma de governo, templos, culto e religião; tem plantações, são cultivadores; tem mulheres claras e algumas têm traços de belleza. Não tomam ellas parte no culto, sendo-lhes prohibida a entrada no templo e obrigadas a ignorar os nomes e fórmas dos idolos, que não tèm fórma humana, são figuras geometricas, feitos de madeira fina polida. O maioral ou pai dos deuses chama-se Epimará, tèm fórma ellipsoide e poderá ter em dimensão o comprimento de 35 a 40 centimetros. Tem fetiches de pedras polidas de fórmas e tamanhos diferentes. (LABRE, 1888, p. 109).

Dez índios de Mamuyeçada acompanharam a expedição como guias e carregadores de bagagens, e o chefe Tata-Chumo voltou para a sua maloca. A povoação tinha dois chefes, Tata Capa e Tata Hynyvéne (LABRE, 2016, p. 189). Seguindo para oeste, Labre encontrou outra maloca Araúna abandonada de nome Hatataeçada ${ }^{3}$ que distava $3 \mathrm{~km}$ do porto de Capa (nome de um chefe Araúna). Dessa maloca abandonada, Labre e seus expedicionários pernoitaram em uma corrente d'água chamada Aruanaeçada (LABRE, 1888, p. 109-10).

Além de encontrar esses povoados e templos dos Araúna, Labre também esteve em contato com outros povos. Primeiro na taba Cuinêputhsúa, povoação deixada, ou seja, semiabandonada, mas ainda possuía uma boa casa, um pequeno templo, pátio limpo de forma circular e tinha como chefe Tata Runa; e depois na aldeia Tupenaputhsúa, chefiada também por Tata Runa, mas com um segundo chefe de nome Cunuparo; ambas Pacaguara, que segundo Labre, eram

\footnotetext{
2 Tata-ecue significa "amo" ou "superior" em Araona (PAZ, 1895, p. 66).

${ }^{3}$ Mesmo nome da primeira tapera Araúna.
} 
agricultores e tinham os mesmos hábitos, costumes e religião de seus vizinhos Araúna (LABRE, 1888, p. 110).

Esses Pacaguara, em troca de presentes, levaram Labre aos Guarayo que eram seus aliados. É importante notar que Labre relata que existiam dois Guarayo na aldeia Tupenaputhsúa, ligados por laços de família, os quais se comprometeram a levar os expedicionários a sua "nação" (LABRE, 1888, p. 110).

Para chegar à povoação dos Guarayo, os expedicionários se despediram dos índios Araúna e foram acompanhados somente de índios Pacaguara e dos dois Guarayo. Labre passou por uma pequena maloca Pacaguara, atravessou igarapés, pernoitou em um Porto chamado Guarayo; teve de atravessar o rio Abunã (Caramánu), andou por densa floresta passando por grandes povoações indígenas abandonadas; caminhou por antigas estradas selvagens e, depois de três dias de caminhada, encontrou uma povoação abandonada de nome Huatchaputhsúa dos Guarayo. Essa povoação possuía uma casa grande e um templo fechado que ainda conservava muitos ídolos, enfeites e instrumentos de guerra (LABRE, 1888, p. 111). Segundo Labre, “n'esta povoação ouve antigamente uma grande tribu, segundo annuncia a área, em torno da habitação, formando um circulo perfeito com o diâmetro de um kilometro" (LABRE, 2016, p. 191).

No dia seguinte, chegaram à povoação de Timbyamyhan dos Guarayo, cujos chefes eram Tata Cumarúhuá, Tata Cahaaty e Tata Cayuary. Os dois últimos chefes junto com Tata Cunuparo e mais oito índios carregadores continuaram a exploração, enquanto o restante dos Pacaguara foram dispensados. Os expedicionários chegaram a uma maloca deserta que tinha um "prado artificial com uma circunferencia de 5 kilômetros, tendo ao centro duas grandes casas já abandonadas, porém limpas, e ainda guardavam grandes caldeirões de barro queimado de mais de 1 metro de altura e diversos objectos e enfeites guardados em tecidos de palha" (LABRE, 1888, p. 112). Nesse lugar, havia um índio que vigiava plantações de coca que eram habituados a usar.

A referência a esses lugares desflorestados parece comum no relato de Labre, ele diz ter passado por um campinho de 1.500 metros de circunferência que os Guarayo diziam ser lugares de antigas plantações ou ainda quando menciona passagens por campinhos com sinais de antigas moradias selvagens (LABRE, 2016, p. 192). 
Os expedicionários seguiram para um lugar chamado Canamary, mas, antes, passaram por povoações antigas, encruzilhadas e estradas. Labre chegou a outro campo (prado artificial), onde encontrou uma choça com oito índios, "affirmaram elles ser natural aquelle prado ; poderia ter 5 kilometros de comprido sobre 3 kilometros de largo" (LABRE, 1888, p. 112). No mesmo dia, Labre chegou a Canamary e a descreveu como uma cidade selvagem com cinco ou seis malocas, uma próxima da outra. Uma das malocas ficou descontente com a visita dos expedicionários e ameaçaram de morte o chefe Cunuparo por ter "conduzido gente branca inimiga!" (LABRE, 1888, p. 113), o que gerou medo no chefe Pacaguara. Ainda assim, no dia seguinte, dois chefes de nome Tucano e Hyacapareh acompanharam Labre junto com 15 índios carregadores em troca de presentes.

A expedição seguiu passando por povoações cujos índios fugiam para evitar o contato, mostrando grupos indígenas numerosos, moradores de longa data que viviam especialmente da lavoura. Labre conseguiu convencer um chefe e cinco índios a acompanhar a expedição (LABRE, 2016, p. 193-4). Eles chegaram na maloca Camarana, que possuía duas tabas e dois chefes, Antonio e Manuel Joaquim. Veja-se que o nome dos chefes são antropônimos de contato. Os Camarana acompanharam os exploradores, juntos exploraram o território dos Ypunãs, que fugiram do contato. Os viajantes contornaram um brejo que tomou o nome de Brejo da Ponte. Posteriormente, alguns Camarana junto com o chefe Manuel Joaquim abandonaram a expedição (LABRE, 1888, p. 113-4).

No dia 30 de agosto, os Camarana que continuaram junto com os exploradores, finalmente levaram Labre ao rio Acre, esses índios chamavam esse rio de Muchanguy. Labre relata a alegria de encontrar esse rio e explica que, após dispensar os Camarana, hospedou-se em um sítio chamado Flor do Ouro (Figura 1). Esse lugar dista $18 \mathrm{~km}$ da povoação comercial de Nova York, onde navegava vapores do Pará e Manaus (LABRE, 1888, p. 114; 2016, p. 193). O caminho alternativo que foi proposto por Labre, iniciava-se no sítio Flor do Ouro no rio Acre e encerrava-se no porto Amapo, rio Madre de Dios.

\section{HISTÓRIA INDÍGENA E NOMINALISMO}

A segunda metade do século XIX é marcada por diversas explorações na Amazônia, dentre elas, aquelas que se dedicaram ao extrativismo, especificamente 
a coleta da goma elástica. O boom da borracha se intensificou a partir da bacia do rio Purus, logo, os rios Madre de Dios e Acre foram tomados pela economia do caúcho. A imagem desse período é a de diversas povoações da seringa às margens dos rios, a exploração de trabalhadores vindos do nordeste brasileiro e a escravidão sobre as populações indígenas.

A década de 1870 é apontada como o auge da exploração da goma elástica na bacia do rio Purus. A história do Acre utiliza esse evento como o marco fundador da trajetória acriana, onde a figura do seringueiro é imortalizada como protagonista no meio da floresta.

Na historiografia acriana, a diversidade nativa se confunde, geralmente, com a natureza a ser explorada e conquistada ou, na melhor das hipóteses, é apresentada como um estado primitivo de humanidade. Antes da epopeia da borracha e da chegada dos seringueiros, a região acriana é tida como não tendo história. (PIMENTA, 2015, p. 336).

Nesse caso, o desafio da história indígena reside não apenas em não recusar os índios da história, mas em apontar caminhos de sua trajetória que aparecem explícitos ou implícitos nos relatos históricos do sudoeste amazônico. Os rios Madre de Dios e Acre estavam contaminados pela "febre do caúcho", porém diversos povos que habitavam a área de terra firme ainda não tinham sido contatados diretamente, isso ocorre durante a viagem do coronel Labre, que registra diferentes nomes de grupos indígenas, com uma descrição peculiar sobre suas formas de ocupar o espaço, suas instituições sociais, assim como sua estranha linguagem. Essas são razões suficientes para que se investigue a história desses povos, sobretudo amparada pela arqueologia que avançou sobre a fronteira Brasil-Bolívia no século XXI.

Os Araúna ou Araona são povos da família linguística Takana, enquanto os Pacaguara são Pano. Labre (1888, p. 110) notou que ambos os grupos falavam dialetos diferentes, portanto compreendiam-se. O registro dos Pacaguara nessa região é incomum, uma vez que esses povos estavam mais a noroeste de onde são tradicionalmente registrados na etno-história, junto a outros diversos etnônimos, conhecidos sob a categoria de Pano meridionais no interflúvio Beni-Mamoré (CÓRDOBA; VILLAR, 2009; VILLAR; CÓRDOBA; COMBÉS, 2009).

Guarayo é um etnônimo genérico dado pelos moradores do império incaico a qualquer índio amazônico que portasse tanga (palavra provavelmente 
Quíchua, wara "tanga", yuh "portador de"), mas, ao longo da conquista ibérica, foi gradativamente utilizado por missionários para nomear índios irredutíveis e passou a designar diversos grupos amazônicos de línguas das famílias Tupi-Guarani, Chapakura, Pano e Takana (RAMIREZ, 2010, p. 22). Segundo Labre, esses Guarayo em tudo se parecem com seus aliados Pacaguara e apresentam um dialeto diferente (LABRE, 2016, p. 210). Church (1912, p. 127-8), explica que os Guarayo, os mesmos que estão no relato de Labre, possuem as mesmas práticas, costumes e economias dos Pacaguara, e que se acreditava que pertenciam a "tribo" dos Caripuna (Pano) das cachoeiras do rio Madeira. Portanto tudo indica que esses Guarayo eram falantes Pano, assim como seus vizinhos Pacaguara ${ }^{4}$.

É difícil inferir se os Pacaguara e Guarayo já estavam nesse local há mais tempo, ou se foram "empurrados" pela colonização, ou ainda por outros povos indígenas para essa área. Outro registro documenta que os Araona temiam muito os Guarayo, cujos encontros eram marcados por guerras (PAZ, 1895, p. 64).

Canamary ou Kanamarí pode referir-se a povos das famílias linguísticas Katukina, Pano e Arawak. Além de etnônimo é um etnotopônimo se referindo à cidade selvagem de Canamary. Os interpretes de Labre não compreenderam a língua desses índios (LABRE, 2016, p. 193), o que não contribui para apontar a que família linguística poderia corresponder. Nimuendajú (1981) localizou os Kanamarí (Arawak) nos rios Iquiri/Ituxi e Yaco; Kanamarí (Katukina) nos rios Yuruparí, Pahuiní e Tapauá; e Kanamarí (Pano) no rio Purus. Nesse quadro, aqueles que mais se aproximam da rota de Labre são os de língua Arawak.

Chandless (1866a; 1866b), ao localizar diversos Kanamarí de língua Arawak, apontou que aqueles que viviam no rio Yaco eram conhecidos dos Ipurinãs (Arawak) por realizarem casamentos, mas rivais dos Manchineri (Arawak).

Os Camarana, parecem ser povos falantes das línguas Arawak que habitavam os rios Acre e Purus (CHAMBERLAIN, 1913, p. 477). Em relação aos Ypunãs, não foi possível apontar qualquer vínculo linguístico.

O espaço percorrido por Labre entre os rios Madre de Dios e Acre mostra vários povos, mas aparece no mapa das Áreas Etnográficas da América Indígena

\footnotetext{
${ }^{4}$ Os Esse-ejja (Takana) ocuparam os rios Madre de Dios e alguns de seus afluentes, foram igualmente designados como Guarayo durante a colonização (cf. RAMIREZ, 2010).
} 
(Rio Beni) de Melatti (2016, p. 3) como uma área praticamente vazia. Um antigo mapa etnográfico de Ehrenreich (1891) mostra um "cordão" Arawak no alto rio Purus, cujo interior é grafado em letras grandes o nome Ipurina (Apurinã) e em letras menores outros etnônimos, são eles: Catiana, Kanamary, Manetenery e Uinamary. No mesmo mapa de Enrenreich é possível visualizar na margem direita do rio Madre de Dios os Pacauara (Pano), Arauna e Guarayo (Tupi) ${ }^{5}$. Já no mapa etno-histórico de Nimuendajú (1981), há a presença de grupos da família linguística Takana com o registro dos Araona e Kapechene, assim como dos Arawak representados pelos Apurinã e Kanamarí nas imediações do rio Acre.

O mapa que mais se aproxima da descrição de Labre é o de Eriksen (2011, p. 34), no qual são apontadas a localização das famílias linguísticas Pano e Takana entre os rios Madre de Dios e Abunã, e Katukina e Arawak na outra banda esquerda do rio Abunã em direção ao rio Acre. Ainda assim, o relato de Labre mostra um território bastante dinamizado; em quilômetros percorridos pelo explorador, encontravam-se malocas, tabas, taperas, caminhos e estradas de povos que falavam línguas distintas, que se dedicavam à agricultura e possuíam templos sagrados. Esses povos que sabiam da existência um do outro provavelmente trocavam informações e bens materiais, fato que Labre notou quando apontou algumas similaridades linguísticas entre os Araona, Pacaguara e Guarayo.

Diversos linguistas têm discutido as hipóteses de parentesco genético e de empréstimos linguísticos por contatos entre as línguas Pano e Takana, mas sem apresentar um consenso. Fleck (2013, p. 21) propõe que a origem dos "proto-Pano" localiza-se no centro leste do Peru e na porção mais ocidental do Brasil, onde está situada a maior parte das línguas Pano. Embora não descarte a possibilidade de outras origens pré-históricas, ele aponta que a relação Pano e Takana não está adequadamente demonstrada, por isso é difícil inferir uma origem Pano na Bolívia. No entanto outros linguistas "consideran que las numerosas semejanzas léxicas y gramaticales observables entre Pano y Takana son el resultado tanto del parentesco genético como del contacto linguístico antiguo y relativamente reciente" (VALENZUELA; GUILLAUME, 2016, p. 21). A relação entre essas famílias

\footnotetext{
${ }^{5}$ Até o fim do século XIX Guarayo era um etnônimo que designava somente povos da família linguística Tupi-Guarani, daí a razão para que os Guarayo do mapa de Ehrenreich fossem grafados como Tupi.
} 
linguísticas combinadas com evidências arqueológicas deu origem à hipótese da gênese Pano-Takana entre os rios Beni e Guaporé, onde historicamente ocuparam os Pano meridionais (LATHRAP, 1970; ERIKSON, 1992).

A descrição de Labre apresenta um elo com as evidências arqueológicas do Estado do Acre por se localizarem geograficamente na mesma área. Mais precisamente entre os rios Abunã e Acre, onde se encontram diversos sítios arqueológicos conhecidos como geoglifos. A menção a um prado artificial com $5 \mathrm{~km}$ de circunferência é sugestiva, pois os espaços desses geoglifos foram, no passado, áreas desflorestadas, e o no seu entorno, florestas antropizadas (WATLING et al., 2017). Ao mencionar antigas casas, templos abandonados, caldeirões de barro e outros objetos, a descrição de Labre parece não deixar muitas dúvidas de uma ocupação indígena recente desses recintos. Informações dos templos dos Guarayo endossam essa associação ao mencionar muralhas de barro erigidas na circunferência das casas para impedir a entrada de água da chuva e de animais, ou ainda quando se relata que, além das plumas e armas, havia também potes de barro, alguns com faces humanas e outros com morfologias de animais ( $\mathrm{CHURCH}$, 1912; LABRE, 2016, p. 210). Essa descrição apresenta correspondências com as evidências arqueológicas encontradas na mesma região, há diversos geoglifos com muretas, e a presença de artefatos zoo e antropomorfos (BARBOSA, 2014; SAUNALUOMA; VIRTANEN, 2015, p. 30; SCHAAN, 2008).

Os geoglifos com suas valetas e muretas de morfologias geométricas (Figura 2 ), incluindo longos caminhos lineares associados a esses recintos, provavelmente foram lugares de encontros sociais ou espaços cerimoniais constituídos por sociedades heterárquicas com um sistema político, ideológico e religioso capaz de conduzir esses povos à construção de obras monumentais (SAUNALUOMA; SCHAAN, 2012; SCHAAN, 2012). Embora não exista elementos para mostrar uma continuidade direta entre os povos que construíram esses lugares, e os grupos que o habitavam à época do contato no meio do século XIX, o relato de Labre reforça alguns aspectos persistentes quando descreve diversos caminhos ou estradas, malocas com templos sagrados e "prados artificiais" na mesma área geográfica dos geog lifos do leste do Acre ou das zanjas do Departamento de Pando na Bolívia. É possível que o território que compreende o interflúvio Orton e Abunã no norte da Bolívia, possa existir mais zanjas. Atualmente a área é coberta por florestas, o que não permite identificar imediatamente essas construções. 


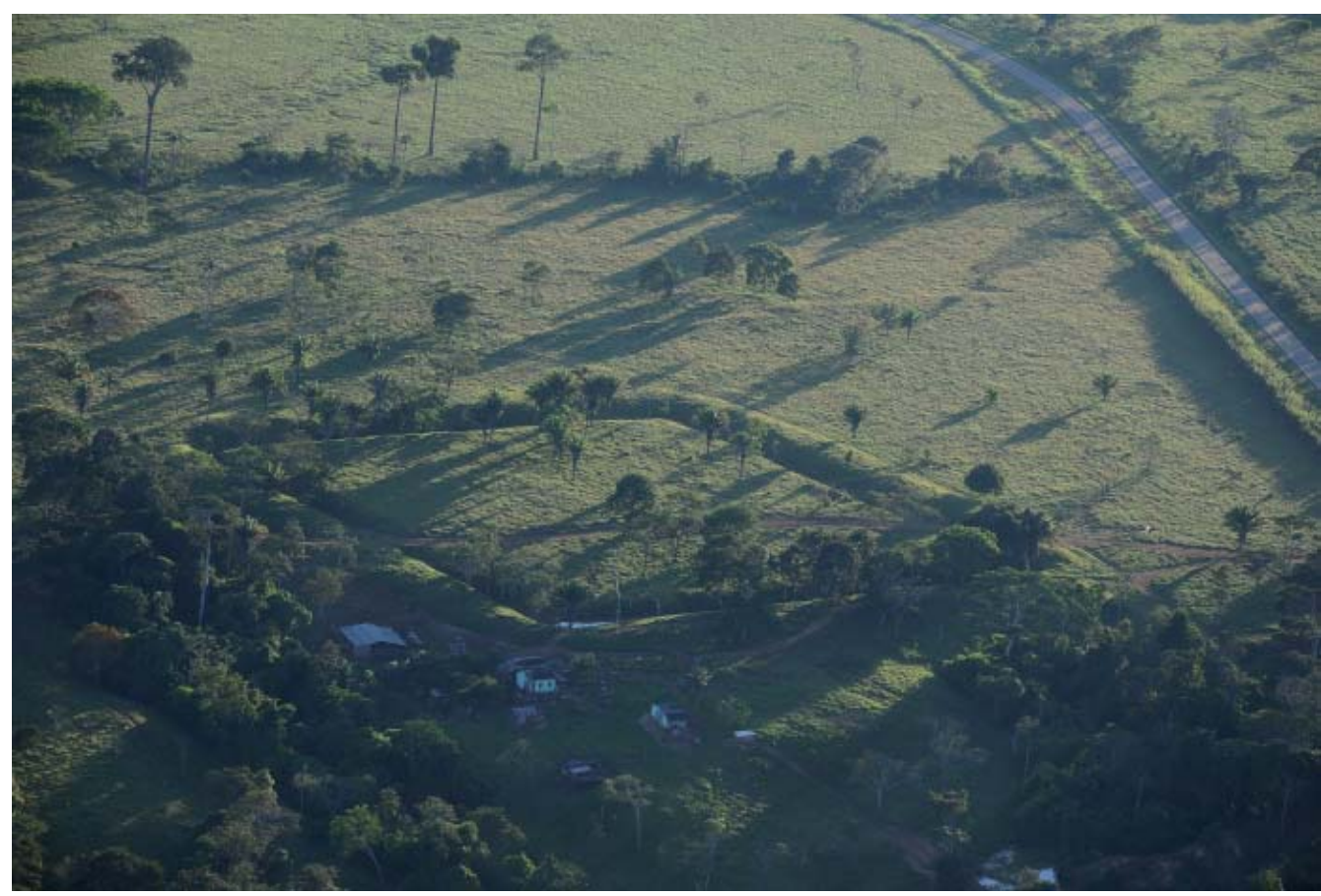

Figura 2 - Geoglifo no Estado do Acre, Brasil.

Foto: Diego Gurgel.

A descrição de uma povoação Araona (Mamuyeçada) já havia chamado a atenção de arqueólogos(as) que pesquisam os sítios com estruturas de terra geométricas (geoglifos) no Estado do Acre, pela localização desses templos e do culto a ídolos com morfologias geométricas (BARBOSA, 2014, p. 51-2). Cerca de cinco centenas de geoglifos que se localizam no Acre, por suas dimensões morfológicas em uma ampla área geográfica, foram interpretados como espaços cerimoniais por sociedades integradas regionalmente (SAUNALUOMA; VIRTANEN, 2015; SCHAAN, 2012, p. 170-1). Os templos abandonados vistos por Labre coincidem com o uso esporádico do espaço interno dos geoglifos, em oposição à pouca evidência doméstica e residencial (SAUNALUOMA; SCHAAN, 2012). De fato, não apenas os Araona como também os Pacaguara e Guarayo parecem ter construído templos e, em alguns casos, em áreas desflorestadas que impressionaram Labre.

Esses templos se assemelham à casa dos homens dos Caripuna e Chacobo, outros grupos Pano que ocuparam o interflúvio Beni-Mamoré e as cachoeiras do rio 
Madeira, onde também há registros de geoglifos. Em Francisco Xavier Negrete, há um relato de 1795 sobre índios possivelmente Pacaguara, que habitavam o baixo rio Mamoré, próximo à cachoeira de Bananeiras, cujas casas eram distintas para mulheres e homens, sendo o interior da casa dos homens composta por objetos festivos e ferramentas de guerra (VILLAR; CÓRDOBA; COMBÉS, 2009, p. 129).

A casa dos homens Caripuna foi descrita por Keller (1875, p. 147-8) como um espaço de reuniões; dentro da casa, havia tambores para festas, cestas feitas com palhas e enfeites de penas, flechas suspensas e cavidades no solo que revelaram cinco urnas funerárias cerâmicas. Assim como nos templos Araona mencionados por Labre, as mulheres não participavam das atividades no interior da casa dos homens. Nesse caso, a casa dos homens era um local de reverência e onde os mais honrados guerreiros eram enterrados; foi nesse espaço que ocorreram as trocas dos objetos coloniais (facas, tesouras, anzóis de pesca, lenços, etc.) trazidos por Keller, o qual recebeu dos nativos macaxeira, milho e armas.

Erikson (2014, p. 399-400) descreve um ritual festivo organizado na casa dos homens (bëpana) Chacobo, segundo o qual se dançava ao redor de um recipiente de chicha de milho, hoje comumente de mandioca, em cantos e toques de zampoñas que envolvia rivalidade entre anfitriões e convidados. A competição de bebidas se dava na disposição dos convidados em chegar à casa dos homens, uma vez que, entre o porto e a aldeia, havia uma trincheira (zanja) de dezenas de metros que canalizava o percurso dos convidados, também chamada de "caminho dos recipientes de cerâmica", trajeto acompanhado de vasilhas com chicha que os convidados deveriam consumir e, às vezes, se tornavam incapazes de chegar à casa dos homens.

O templo ou casa dos homens representam uma instituição em comum entre os falantes das línguas Takana e Pano: "Los pacaguaras, caripunas y garayos, tienen muchas semejanzas em sus usos e culto, y no difieren de los araonas" (PAZ, 1895, p. 65).

Uma hipótese arqueológica aponta que os geoglifos quadrangulares que predominam ao norte poderiam ter sido construídos por povos falantes das línguas Arawak, enquanto os circulares localizados ao sul teriam sido construídos por povos falantes das línguas Takana (SCHAAN, 2012). As informações de Labre colocam outros grupos linguísticos (Pano e Takana) no bojo pré-colonial dos geoglifos e 
zanjas do sudoeste amazônico, obras que são comumente associadas com grupos de matriz Arawak na Amazônia (HECKENBERGER, 2005; VIRTANEN, 2008).

As interpretações apresentadas escapam do modelo difusionista clássico da etnologia americanista. Particularmente quando Métraux (1942, p. 4, 41-4) propôs que a "elaborada" cultura material Araona (madeiras esculpidas decoradas, objetos como lanças, machados, potes de cerâmicas ou pequenos seixos), representando ídolos no interior de templos quadrados localizados no meio da floresta, seria uma influência recente da cultura Inca na Amazônia.

Os dados históricos do século XIX mostram povos da Amazônia ocidental, após o impacto do primeiro boom da borracha, apresentando socialidades próximas daquelas dos povos que construíram os geoglifos há mil anos no Acre. Apesar de os povos de língua Pano ter um ethos mais predatório, a etnogênese dessa família linguística tem sido vinculada a uma profunda relação com os Arawak no sudoeste amazônico, um processo sociocultural contínuo de negociação interétnica, incorporação e emulação centrada na reprodução de uma identidade regional comum (HORNBORG; ERIKSEN, 2011).

As informações fornecidas por Labre reportam-se ao culto a ídolos e a relação com a paisagem. Deixam transparecer um ar de poder entre esses povos, especialmente quando negocia diretamente com os chefes, o que poderia denotar o respeito a uma autoridade. Chefes poderosos chamados chama chamarria foram apontados como tendo privilégios e poderes destacados entre os Chacobo da Amazônia boliviana que converge com o modelo clastriano do líder sem poder (ERIKSON, 2009). O ethos Arawak é descrito como de um povo de caráter aberto para as relações, incluindo alianças, a reprodução de hierarquias, formações sociais regionais organizadas em torno de lugares sagrados, apropriação da paisagem e a construção de topônimos (HECKENBERGER, 2005; HILL; SANTOS-GRANERO, 2002).

Não é o caso de atribuir um vínculo de construção dessas obras a esses grupos etno-linguísticos que ocupavam do Madre de Dios ao Acre, até porque mais de quatro séculos separam as datações arqueológicas obtidas nos geoglifos dos topônimos e etnônimos descritos por Labre. Ao mesmo tempo, apesar do efeito devastador que o contato colonizador provocou entre esses grupos - especialmente por se tratar do século XIX, embora essas sociedades se encontrassem 
em relativo estado de isolamento em relação à colonização em virtude da área geográfica que ocupavam -, não se pode recusar a evidente continuidade histórica que pode existir entre os contextos arqueológicos e a narrativa histórica. A propósito dessa questão, a etnologia brasileira já realizou crítica às pesquisas que apontam para uma ruptura rígida entre pré e pós-conquista (FAUSTO, 1992, p. 381; VIVEIROS DE CASTRO, 1993), de modo que o efeito do contato, especialmente aquele do impacto demográfico, político e econômico nas sociedades ameríndias, não pode ser utilizado como índice capaz de extinguir permanentemente as estruturas sociopolíticas, cosmologias e concepções de etnicidade.

O quadro desenhado pela antropologia mostra como a longa história indígena possui uma trama que muda severamente com o contato, sobretudo as redes de interações de longa distância. De outro modo, a classificação dos agentes colonizadores sobre os indígenas acabou por "essencializar" esses povos por meio de etnônimos:

O mundo ameríndio pré-colombiano era um tecido mais ou menos denso, mas sem falhas, em estado de fluxo constante, composto de gigantescos sistemas regionais que articulavam regiões tão distantes como a montaña peruana e a bacia do Orinoco, os Andes e o litoral de São Paulo. Fragmentos destes vastos complexos de troca comercial e cultural, matrimonial e guerreira, podem-se ver ainda hoje no rio Negro, no Alto Xingu, na Amazônia sub-andina ou no escudo da Guiana. O congelamento e o isolamento das etnias é um fenômeno sociológico e cognitivo pós-colombiano; a multiplicação de etnônimos nas crônicas e relatórios antigos é fruto de uma incompreensão total da dinâmica étnica e política do socius ameríndio, incompreensão baseada em um conceito inadequado de sociedade, substantivista e "nacional-territorialista", incapaz de dar conta da natureza relativa e relacional das categorias étnicas, políticas e sociais indígenas. (VIVEIROS DE CASTRO, 1993, p. 31-2).

Se, em um primeiro momento, os etnônimos, que são em sua maioria nomes derrogatórios dado por outros grupos indígenas, serviram para delimitar diversos substratos étnico-linguísticos, em outros, integraram, debaixo de um único etnônimo, diversos coletivos. Guarayo, por exemplo, um pronome pejorativo, apresenta-se como um etnônimo genérico propagado pela colonização, dissolveu a diversidade de grupos de pelo menos quatro famílias linguísticas. Em uma reinterpretação da crítica de Viveiros de Castro, Monteiro (2001, p. 57), entende que "pelo menos para as terras baixas da América do Sul, o mosaico etno-histórico 
do mapa pós-contato contrasta com um panorama pré-colombiano que mais se assemelha a um caleidoscópio".

É evidente que os etnônimos fornecidos por Labre parecem representar grupos distintos separados por uma fronteira imaginável, cada um com sua maloca/ taba, templo sagrado e sua roça. Mas as semelhanças encontradas entre esses povos, por vezes linguísticas, pode ser a evidência de sociedades que estavam integradas regionalmente.

Labre, ao tentar mostrar uma rota de ligação do Madre de Dios ao Acre, esboçou um cenário de grupos indígenas que já tinham seus próprios caminhos e o ajudaram a fazer a conexão entre os dois rios. Esse relato histórico contribui para realçar a profunda trajetória dos geoglifos na história amazônica. Em outras palavras, trata-se de reconhecer que os Araona, Pacaguara, Guarayo, Camarana, Canamary e Ypunã, estavam ao menos reocupando essas áreas e significando as paisagens de alguma forma.

A expedição de Labre teve o mérito de realizar o registro de diversos lugares que são topônimos nas línguas indígenas, sendo alguns deles etnotopônimos (estrada Araona, estrada Guaraya, estrada Cuinê, caminho de Timbyamyhan, entre outros). Observa-se também que enquanto Labre explorava o território dominado pelos Araona, os topônimos tinham sufixos - eçada, e quando ele passa para territórios Pacaguara e Guarayo os topônimos passam a ter os sufixos - puthsúa. Essas menções fazem alusão a lugares importantes (malocas, tabas, taperas, caminhos e estradas) que estavam estabelecidos e se espalhavam por um largo território caracterizado por grupos indígenas, praticamente sem contato com o colonizador branco. Apesar da importância desse registro, não há informação da permanência da maioria desses topônimos ao longo do tempo, exceção de alguns poucos que se fixaram, como é o caso do famoso rio Acre que é a corruptela de rio Uakíry.

Sobre a história do rio Acre, Pinkas (1887, p. 286) lembra que o nome Aqui-are (Ucayari, Aquiry) era utilizado pelos índios para se referir indistintamente aos rios Madeira, Beni e Madre de Dios. Nesse sentido, muitos viajantes acreditavam erroneamente que o Madre de Dios desaguava no Purus por meio do rio Acre. Assim, os nomes desses rios seriam os mesmos e revelariam um único significado:

Aqui-are, portanto, pôde traduzir-se - oh! quanta madeira! - e dessa exclamação naturalmente deriva o Madeira seu nome actual, bem como seu 
nome antigo de Ucayare, como degeneração de Aqui-are, Uqui-ari, Ucai-ari (o índio exprime o $i$ final aspirado de fôrma a deixar a duvida si é um e ou um $i$ que deve ser escripto). (PINKAS, 1887, p. 286-7).

Caiary era como os índios chamavam o rio Madeira no início da conquista europeia registrado pelo padre Cristobal Acuña em 1641 (ACUÑA, 1994, p. 171). Caiary, Uakiry ou Aquiry pode ter sido um nome comum que designou no passado os rios Madre de Dios, Beni, Madeira e Acre que são responsáveis por levar por suas correntezas uma grande quantidade de madeiras anualmente. Ucayari era também o nome de um povo que habitava o rio Uaupés, rio este que levava antes o mesmo nome dessa etnia (PORRO, 2007, p. 102, 139). Os Cauari da região do rio Negro, Guaviare, Içana, Yapurá (Caquetá), Apaporís, poderiam ser Arawak (CHAMBERLAIN, 1913, p. 478, 483). É bom lembrar que Cayuary era o nome de um dos chefes Guarayo (Pano). Labre (1888, p. 102) escreveu que Uakiry provinha dos índios Apurinã, e esse nome é hoje utilizado como sufixo numa autodenominação desse grupo: Pupỹkarywakyry (FACUNDES, 2000, p. 3). Como se observa, Uakiry é ilustrativo para exemplificar a dificuldade em inferir se tais nomes são apenas nomes, pronomes, etnônimos, topônimos ou ainda, etnotopônimos.

\section{CONSIDERAÇÕES FINAIS}

O relato colonialista do coronel Labre, que ansiava encontrar um caminho na floresta para os seus negócios e levar os índios ao caminho da civilização, acabou por descrever uma terra emblemática habitada por diversos povos indígenas com suas instituições sociopolíticas e chefias próprias. Como observou Rocha (2016, p. 118), Labre não formulou um pensamento sobre a região que estava para ser colonizada, "ele ouviu e apreendeu a partir dos nativos".

O que parecia uma floresta intocada, abrigava um complexo cenário étnico com sinais claros e particulares de alteração na paisagem, modificações essas essenciais para compreensão do registro arqueológico pré-colonial deixado pelas populações indígenas que habitam ainda hoje a Amazônia. A extensão de terra firme percorrida por Labre, delimitada pelo rio Madre de Dios ao rio Acre era também multilinguística. A constatação desse quadro só é possível quando se parte de enfoques interdisciplinares. O desafio da história indígena consiste em encorajar essas abordagens para a construção de uma trajetória de longa duração. 


\section{Agradecimento}

O autor agradece a Angislaine Costa pela colaboração e discussão sobre história indígena na Amazônia meridional.

\section{REFERÊNCIAS}

ACUNÃ, Cristóbal de. Novo descobrimento do rio Amazonas. Tradução de Antônio R. Esteves. Montevidéu: Consejería de educación de la embajada de España en Brasil, 1994.

AIKHENVALD, Aleksandra Yurievna. Language contact in Amazonia. Oxford: Oxford University Press on Demand, 2002.

BARBOSA, Antonia Damasceno. Análise espacial dos sítios monumentais do leste da Amazônia ocidental. 2014. 227f. Dissertação (Mestrado em Antropologia) - Universidade Federal do Pará, Belém, 2014.

CALAVIA SÁEZ, Oscar. Nomes, pronomes e categorias: repensando os "Sub-grupos" numa etnologia pós-social. Antropologia em primeira mão, Florianópolis, v. 138, p. 5-17, 2013.

CAVALCANTE, Thiago Leandro Vieira. Etno-história e história indígena: questões sobre conceitos, métodos e relevância da pesquisa. História, São Paulo, v. 30, n. 1, p. 349-71, jan./jun. 2011.

CHANDLESS, William. Ascent of the river Purus. The Journal of the Royal Geographical Society of London, Londres, v. 36, p. 86-118, 1866a.

. Notes on the river Aquiry, the principal affluent of the River Purus. Journal of the Royal Geographical Society, Londres, v. 36, p. 119-28, 1866b.

CHAMBERLAIN, Alexander Francis. nomenclature and distribution of the principal tribes and sub-tribes of the Arawakan Linguistic Stock of South America. Journal de la Société des Américanistes, v. 10, p. 473-96, 1913.

CHURCH, George Earl. Aborigines of South America. London: Chapman and Hall; Limited, 1912.

CÓRDOBA, Lorena; VILLAR, Diego. Etnonimia y relaciones interétnicas entre los panos meridionales (siglos XVII-XX). Revista Andina, Cuzco, n. 49, p. 211-44, 2009.

CORRÊA, Ângelo Alves. Longue durée: história indígena e arqueologia. Ciência e Cultura, São Paulo, v. 65, n. 2, p. 26-9, abr./jun. 2013.

EHRENREICH, Paul. Die Einteilung und Verbreitung der Völkerstämme Brasiliens nach dem gegenwärtigen Stande unsrer Kenntnisse. Petermanns Mitteilungen aus Justus Perthes' geographischer Anstalt, Gotha, v. 37, p. 81-9, 114-24, 1891. 
ERIKSEN, Love. Nature and Culture in Prehistoric Amazonia Using GIS to reconstruct ancient ethnogenetic processes from archaeology, linguistics, geography, and ethnohistory. Lund: Lund University, 2011.

ERIKSON, Philippe. El ritual como máquina del tiempo: ejemplos chacobo (Amazonía boliviana). In: ROSTAIN, Stephen (Ed.). Antes de Orellana - Actas del 3er Encuentro Internacional de Arqueología Amazónica. Lima: Instituto Francés de Estudios Andino, 2014. p. 399-406.

. Diálogos à flor da pele... Notas sobre as saudações na Amazônia. Campos - Revista de Antropologia Social, v. 10, n. 1, p. 9-27, 2009.

. Uma singular pluralidade: a etno-história Pano. In: CUNHA, Manuela Carneiro da (Org.). História dos índios do Brasil. São Paulo: Companhia das Letras, 1992. p. 239-52.

FACUNDES, Sidney da Silva. The language of the Apurinã people of Brazil (Maipure/ Arawak). Buffalo: University of New York, 2000.

FAUSTO, Carlos. Fragmentos de história e cultura tupinambá: da etnologia como instrumento crítico de conhecimento etno-histórico. In: CUNHA, Manuela Carneiro da (Org.). História dos índios do Brasil. São Paulo: Companhia das Letras, 1992. p. 381-96.

FLECK, David William. Panoan languages and linguistics. Anthropological papers of the American Museum of Natural History, New York, n. 99, 2013.

FREITAS, Edinaldo Bezerra de. Fala de índio, história do Brasil: o desafio da etno-história indígena. Revista Historia Oral, v. 7, p. 181-97, 2004.

HECKENBERGER, Michael. The ecology of power: culture, place, and personhood in the southern Amazon, AD 1000-2000. New York and London: Routledge, 2005.

HILL, Jonathan. Etnicidade na Amazônia Antiga: reconstruindo identidades do passado por meio da arqueologia, da linguística e da etno-história. I/ha Revista de Antropologia, v. 15, p. 34-69, 2013.

HILL, Jonathan; SANTOS-GRANERO, Fernando. Comparative arawakan histories: rethinking language family and culture area in Amazonia. Urbana: University of Illinois Press, 2002.

HORNBORG, Alf; HILL, Jonathan. Introduction. In: HORNBORG, Alf; HILL, Jonathan (Ed.). Ethnicity in ancient Amazonian: reconstructing past identities from Archaeology, Linguistic and Etnohistory. Boulder: University Press of Colorado, 2011. p. 1-27.

HORNBORG, Alf; ERIKSEN, Love. An attempt to understand Panoan ethnogenesis in relation to long-term patterns and transformations of regional interaction in Western Amazonia. In: HORNBORG, Alf; HILL, Jonathan (Ed.). Ethnicity in ancient Amazonian: reconstructing 
past identities from Archaeology, Linguistic and Etnohistory. Boulder: University Press of Colorado, 2011. p. 129-51.

KELLER, Franz. The Amazon and Madeira rivers: sketches and descriptions from the note-book of an explorer. Philadelphia: JB Lippincott and Company, 1875.

LABRE, Antonio Rodrigues Pereira. Colonel Labre's explorations in the region between the Beni and Madre de Dios rivers and the Purus. Proceedings of the Royal Geographical Society and Monthly Record of Geography, v. 11, p. 496-502, 1889.

- Viagem exploradora do Rio Madre de Dios ao Acre. Revista da Sociedade de Geografia do Rio de Janeiro, Tomo IV, 2o Boletim, p. 102-14, 1888.

. Itinerário da exploração do Purús ao Beni. In: ROCHA, Hélio. Coronel Labre. p. 181-220. São Carlos: Scienza, 2016.

LATHRAP, Donald. The upper Amazon. London: Thames e Hudson, 1970.

MELATTI, Júlio Cézar. Áreas etnográficas da américa indígena. Rio Beni. Disponível em: <www.juliomelatti.pro.br/>. Acesso em: 10 set. 2016.

MÉTRAUX, Alfred. The native tribes of eastern Bolivia and western Matto Grosso. Washington: Smithsonian Institution; Bureau of American Ethnology, 1942.

MONTEIRO, John Manuel. Tupis, tapuyas e historiadores: estudos de história indígena e do indigenismo. 2001. Tese (Livre Docência) - Universidade Estadual de Campinas, Campinas, 2001.

NEVES, Eduardo Góes. Archaeological cultures and past identities in the pre-colonial Central Amazon. In: HORNBORG, Alf; HILL, Jonathan (Ed.). Ethnicity in ancient Amazonian: reconstructing past identities from Archaeology, Linguistic and Etnohistory. Boulder: University Press of Colorado, 2011. p. 1-27.

NIMUENDAJÚ, Curt. Mapa etno-histórico. Rio de Janeiro: IBGE, 1981.

NOELLI, Francisco Silva. The Tupi: explaining origin and expansions in terms of archaeology and of historical linguistics. Antiquity, v. 72, p. 648-63, 1998.

PACHECO DE OLIVEIRA, João. Uma etnologia dos "índios misturados"? Situação colonial, territorialização e fluxos culturais. Mana, Rio de Janeiro, v. 4, n. 1, p. 47-77, 1998.

PAZ, Román. De Riberalta ao Inambari. La Paz: Imprenta de "el comercio", 1895.

PIMENTA, José. O Amazonismo Acriano e os povos indígenas: revisitando a história do Acre. Amazônica-Revista de Antropologia, Belém, v. 7, n. 2, p. 327-53, 2015.

PINKAS, Julio. O alto Madeira. Revista da Sociedade de Geografia do Rio de Janeiro, Tomo III, 4을 Boletim, p. 269-309, 1887. 
PORRO, Antonio. Dicionário etno-histórico da Amazônia colonial. São Paulo: Universidade de São Paulo, 2007.

RAMIREZ, Henri. Etnônimos e topônimos no rio Madeira (séculos XVI-XX): um sem-número de equívocos. Revista Brasileira de Linguística Antropológica, Brasília, v. 2, p. 13-58, 2010.

ROCHA, Hélio. Coronel Labre. São Carlos: Ed. Scienza, 2016.

SAUNALUOMA, Sanna; SCHAAN, Denise Pahl. Monumentality in Western Amazonian formative societies: geometric ditched enclosures in the Brazilian state of Acre. Antiqua, v. 2, n. 1, p. 1-11, 2012.

SAUNALUOMA, Sanna; VIRTANEN, Pirjo Kristiina. variable models for organization of earthworking communities in upper Purus, southwestern Amazonia: Archaeological and Ethnographic perspectives. Tipiti: Journal of the Society for the Anthropology of Lowland South America, v. 13, p. 23-43, 2015.

SCHAAN, Denise Pahl. Sacred geographies of ancient Amazonia: historical ecology of social complexity. Walnult Creek: Left Coast Press, 2012.

Arqueologia do Acre: do Pronapaba às pesquisas sobre os geoglifos. In: SCHAAN, Denise Pahl; RANZI, Alceu; PÄRSSINEN, Martti (Org.). Arqueologia da Amazônia Ocidental. Os geoglifos do Acre. Belém: EDUFPA, 2008. p. 15-44.

STEWARD, Julian. Handbook of south american Indians. University of Michigan-Dearborn, 1963.

VALENZUELA, Pillar; GUILLAUME, Antoine. Estudios sincrónicos y diacrónicos sobre lenguas Pano y Takana: una introducción. Ameríndia - Revue d'Ethnolinguistique Amérindienne, v. 39, p. 1-49, 2016.

VILLAR, Diego; CÓRDOBA, Lorena; COMBÉS, Isabelle. La reducción imposible: las expediciones del padre Negrete a los pacaguaras (1795-1800). Cochabamba: Instituto de Misionología, 2009.

VIRTANEN, Pirjo Kristiina. Observacões sobre as possíveis relações entre os sítios arqueológicos do Acre e um povo Aruak contemporâneo. In: SCHAAN, Denise Pahl; RANZI, Alceu; PÄRSSINEN, Martti (Org.). Arqueologia da Amazônia Ocidental: os geoglifos do Acre. Belém: EDUFPA, 2008. p. 79-89.

VIVEIROS DE CASTRO, Eduardo. Images of nature and society in Amazonian ethnology. Annual Review of Anthropology, v. 25, p. 179-200, 1996.

. Histórias Ameríndias. Novos Estudos, São Paulo, v. 36, p. 22-33, jul. 1993.

WATLING, Jennifer; IRIARTE, José; MAYLE, Francis; SCHAAN, Denise; PESSENDA, Luiz; LOADER, Neil; STREET-PERROTT, Alayne; DICKAU, Ruth; DAMASCENO, Antonia; RANZI, 
Alceu. Impact of the pre-Columbiam "geoglyph" builders on Amazonian forests. Proceedings of the National Academy of Sciences of the United States of America, v. 14, n. 8, p. 1868-73, fev. 2017. Disponível em: <http://www.pnas.org/content/114/8/1868. abstract>.

\section{Sobre o autor:}

Cliverson Pessoa: Mestre em Antropologia (área de concentração em Arqueologia) pela Universidade Federal do Pará. Professor substituto do Departamento de Arqueologia da Universidade Federal de Rondônia.E-mail: cliverson.pessoa@unir.br

Recebido em 6 de março de 2017

Aprovado para publicação em 23 de agosto 2017 
